\title{
Metabolomics for understanding stomatal movements
}

\author{
David B. Medeiros $(\mathbb{D} \cdot$ Luana M. da Luz $\cdot$ Hellen O. de Oliveira $\cdot$ \\ Wagner L. Araújo • Danilo M. Daloso • Alisdair R. Fernie
}

Received: 15 October 2018/ Accepted: 5 January 2019/Published online: 22 January 2019

(C) The Author(s) 2019

\begin{abstract}
Stomata control the exchange of $\mathrm{CO}_{2}$ and water in land plants. For this reason, plants evolved to quickly respond the surrounding environment and endogenous cues in order to maintain their photosynthetic rates, but avoiding excessive water loss. Although guard cell has been used as model for characterization of signaling pathways, mainly regarding abscisic acid (ABA) response, several important questions about its functioning remain elusive. Recently, transcriptomics, proteomics, and metabolomics studies carried out using guard cells as model have contributed substantially for our understanding on how guard cells sense and respond to relative air humidity, $\mathrm{CO}_{2}, \mathrm{ABA}$, and sucrose. Comparatively, proteomics and metabolomics platforms need substantial improvement to increase the number of analytes detected. However, with the introduction of metabolomics-based technologies, several studies
\end{abstract}

D. B. Medeiros $(\bowtie) \cdot$ A. R. Fernie

Max-Planck-Institut für Molekulare Pflanzenphysiologie, Am Mühlenberg 1, 14476 Potsdam-Golm, Germany

e-mail: medeiros@mpimp-golm.mpg.de

L. M. da Luz · H. O. de Oliveira · W. L. Araújo Max-Planck Partner Group at the Departamento de Biologia Vegetal, Universidade Federal de Viçosa, Viçosa, Minas Gerais 36570-900, Brazil

\section{M. Daloso}

Departamento de Bioquímica e Biologia Molecular, Universidade Federal do Ceará, Fortaleza,

Ceará 60440-970, Brazil have been published increasing our knowledge on guard cell function. Here, we review these new exciting findings as well as discuss the importance of using these new data to improve prediction when modelling stomatal behavior.

Keywords Stomata - Guard cells · Metabolites . Metabolite profiling $\cdot$ Mass spectrometry

\section{Introduction}

Stomata, microscopic pores surrounded by two specialized cells - the guard cells -in the leaf epidermis, control the exchange of carbon dioxide $\left(\mathrm{CO}_{2}\right)$ and water in land plants. Therefore, they are the main gate for two essential process in plants; photosynthesis and transpiration. For this reason, plants need to adapt quickly and efficiently the environment and endogenous cues in order to gain sufficient $\mathrm{CO}_{2}$ to maintain their photosynthetic rates and avoid excessive water loss and thus prevent dehydration (Lawson et al. 2014; Schroeder et al. 2001).

Guard cells have been extensively studied for over a century, and considerable efforts have been made to better understand their structure, development, physiology, and metabolism (Bergmann and Sack 2007; Daloso et al. 2017; Dow and Bergmann 2014; Kim et al. 2010; Mott 2009; Santelia and Lawson 2016). These advances have rendered the guard cell as one of 
the best studied plant cell models for membrane transport, signaling, and homeostasis (Blatt 2000; Engineer et al. 2016; Hetherington and Brownlee 2004; Hills et al. 2012; Israelsson et al. 2006).

Stomatal pores are structurally very simple, but the surrounding guard cells are one of the most specialized cell in land plants. They are morphologically distinguished from other epidermal cells and possess a complex signal transduction network, tightly regulated membrane ion system, and specialized metabolic pathways which modulate guard cell turgor and subsequently promote opening and closure of stomata (Santelia and Lawson 2016). Generally, the stomatal pores open in response to increases in guard cell volume driven by decreases in the water potential of the guard cell as result of the osmolytes accumulation and subsequently water influx. Conversely, during stomatal closure, efflux of osmolytes from guard cells is required with associated increase in guard cell water potential and in turn efflux of water (Assmann and Wang 2001). Potassium $\left(\mathrm{K}^{+}\right)$and chloride $\left(\mathrm{Cl}^{-}\right)$act as the main inorganic ions, while malate ${ }^{2-}$ and sucrose (Suc) are considered as the main organic osmolytes during stomatal movements (Kollist et al. 2014; Roelfsema and Hedrich 2005; Vavasseur and Raghavendra 2005).

Most of the knowledge we have regarding stomatal movements came from the discovery and characterization of several components of the protein transporting system in guard cells (Eisenach and De Angeli 2017; Jezek and Blatt 2017). However, lately guard cell metabolism has been revisited and we have recently witnessed great efforts in assessing the importance of a range of metabolites in the regulation of stomatal function in elegant biochemical and physiological studies. The knowledge from these studies has increased our understanding on how guard cells regulate their primary metabolism through organic acid, sucrose, starch, and lipid biosynthetic and degradative pathways in order to control stomatal movements. Although we discuss some of these studies in the following sections the focus of this review is to give an update on how metabolomics approaches have been applied in guard cells studies rather than providing an overview of the regulation of guard cell metabolism for which several recent reviews document the most important recent findings (Daloso et al. 2017; Lima et al. 2018; Santelia and Lawson 2016).
Covering the guard cell metabolome is still not technically viable using a single analytical system but recent developments have considerably extended our ability to analyze this cell type. In fact, recent efforts to comprehend the guard cell metabolome have shed considerable light on metabolic regulation of stomatal movement in response to environmental stimuli. In this review we cover the most recent studies applying guard cell metabolomics approaches in order to understand the roles of important players in stomatal movement such as abscisic acid (ABA), $\mathrm{CO}_{2}$, sucrose, organic acids as well as plant cell-microbe interaction. We further discuss the importance of integrating metabolomics data into mathematical modelling in order to optimize predictions of stomatal behavior under challenging conditions.

\section{Metabolomics studies in guard cells}

While earlier studies on guard cells focused on changes in accumulation of sugars, organic acids, and $\mathrm{K}^{+}$in guard cell (Amoedo et al. 1996; Lu et al. 1995; Talbott and Zeiger 1993, 1996), the recent introduction of new high throughput technologies has reignited guard cell metabolism research. Metabolomics approaches have been applied to analyze changes in guard cell metabolism, being highly useful in providing a broader understanding of guard cell function. However, despite the improvements in guard cell separation methods, all the studies involving guard cell metabolome still face the bottleneck of high quality and rapid cell isolation, in order to disturb as few as possible guard cell primary metabolism. In the last 5 years several studies were published, in which metabolomics approaches were used for answering several unsolved questions on guard cell metabolism, below we review these exciting new findings. The platforms used in each study are summarized in Table 1.

\subsection{Metabolic signatures for ABA response}

Guard cells are well established as a model cell type for deciphering ABA signaling in plants. The regulatory role of $\mathrm{ABA}$ signaling pathway on stomatal regulation has being recently improved by using metabolomics tools. For instance, the metabolic response to $\mathrm{ABA}$ treatment was recently followed in 
Table 1 Technologies applied for metabolomics studies in guard cell

\begin{tabular}{|c|c|c|}
\hline Platform used & Remarks & References \\
\hline LC-MS & $\begin{array}{l}\text { Guard cell protoplasts from Columbia-0 and gpal Arabidopsis plants } \\
\text { subjected in response to ABA }\end{array}$ & Jin et al. (2013) \\
\hline GC-MS/MS and LC-MRM-MS & Mesophyll and guard cells from B. napus subjected in response to $\mathrm{NaHCO}_{3}$ & Misra et al. (2015b) \\
\hline GC-TOF-MS & $\begin{array}{l}\text { Feeding with } \mathrm{NaH}^{13} \mathrm{CO}_{3} \text { in guard cell-enriched epidermal fragments (EF) } \\
\text { from tobacco }\end{array}$ & Daloso et al. (2015) \\
\hline GC-TOF-MS & Feeding with $\mathrm{NaH}^{13} \mathrm{CO}_{3}$ in $\mathrm{EF}$ from transgenic tobacco plants & $\begin{array}{l}\text { Daloso et al. } \\
\text { (2016b) }\end{array}$ \\
\hline $\begin{array}{l}\text { GC-MS/MS, LC-MRM-MS, } \\
\text { and LC-TOF-MS }\end{array}$ & EF from Arabidopsis under $800 \mathrm{ppm} \mathrm{CO}_{2}$ & Geng et al. (2016) \\
\hline $\mathrm{GC}-\mathrm{TOF}-\mathrm{MS}$ & $\begin{array}{l}\text { EF from } t d t \text { Arabidopsis mutant, apoplastic leaflet fluid, and non-aqueous } \\
\text { fractionation samples }\end{array}$ & $\begin{array}{l}\text { Medeiros et al. } \\
\text { (2017) }\end{array}$ \\
\hline GC-MS/MS and LC-TOF-MS & Guard cell protoplasts from $B$. napus in response to ABA & $\begin{array}{l}\text { Zhu and Assmann } \\
\text { (2017) }\end{array}$ \\
\hline GC-TOF-MS & $\begin{array}{l}\text { Validation of modeling flux-based predictions using mesophyll and guard } \\
\text { cell protoplasts fed with } \mathrm{NaH}^{13} \mathrm{CO}_{3}\end{array}$ & $\begin{array}{l}\text { Robaina-Estevez } \\
\text { et al. (2017) }\end{array}$ \\
\hline GC-TOF-MS & Feeding with $\left[\mathrm{U}^{13}{ }^{13} \mathrm{C}\right]$-sucrose in EF from Arabidopsis & $\begin{array}{l}\text { Medeiros et al. } \\
(2018 b)\end{array}$ \\
\hline LC-MRM-MS & $\begin{array}{l}\text { EF incubated with bacteria (Pst DC3000) and labeled with }{ }^{13} \mathrm{C} \text { and }{ }^{15} \mathrm{~N} \\
\text { isotopes }\end{array}$ & Pang et al. (2018) \\
\hline
\end{tabular}

$L C$ liquid chromatography, $M S$ mass spectrometry, $G C$ gas chromatography, $M R M$ multiple reaction monitoring, $T O F$ time of flight

a time-course experiment utilizing liquid chromatography-multiple reaction monitoring-mass spectrometry (LC-MRM-MS) in order to perform targeted analysis of 85 signaling-related metabolites in Arabidopsis guard cell protoplasts (Jin et al. 2013). Arabidopsis wild-type plants and gpal mutants displaying ABA-hyposensitive stomata were evaluated. This targeted metabolomics study revealed, as would perhaps be anticipated, coordinated regulation of signaling metabolites even in unrelated pathways. For instance, hormone related metabolites were more responsive to ABA treatment in wild type than in gpal guard cells. Additionally, the majority of hormones also displayed different $\mathrm{ABA}$ responses in guard cell metabolite profiles when compared with those in the mesophyll cell metabolome, suggesting that ABA is most likely acts upstream of the other hormones (Jin et al. 2013).

More recently, a non-targeted metabolomics study utilizing a combination of gas chromatography-mass spectrometry (GC-MS/MS) and liquid chromatography-time of flight-mass spectrometry (LC-TOF-MS) was applied to identify the metabolic signatures in response to $\mathrm{ABA}$ in $B$. napus guard cell protoplasts
(Zhu and Assmann 2017). Non-targeted metabolomics was used as a complementary approach to targeted metabolomics - providing not only mass/charge ratios but also the mass spectra of all detectable precursor molecules. The platform combination resulted in a metabolite profile of 390 non-redundant metabolites, of which 77 were ABA responsive. On performing an enrichment analysis of the metabolic changes flavone and flavonol biosynthesis and metabolism of amino sugar, nucleotide, sugar, sucrose, and starch were highly affected by ABA (Zhu and Assmann 2017).

Recently, primary metabolism in guard cells has received increased attention mainly regarding the roles of organic acids, sucrose (discussed below) and starch metabolism (we suggest the read of Santelia and Lawson (2016), Santelia and Lunn (2017), and Daloso et al. (2017)). On the other hand, secondary metabolism of guard cells is poorly understood. New insights have, however, been published showing the connection between flavonol biosynthesis and ABA signaling (Watkins et al. 2017, 2014). Flavonol accumulation was observed in guard cells of Arabidopsis, but not in surrounding pavement cells (Watkins et al. 2014). Accordingly, CHALCONE SYNTHASE, a flavonol 
biosynthetic enzyme, was demonstrated to be expressed in guard cells, but not pavement cells. Interestingly, null mutation for the gene encoding CHALCONE SYNTHASE increased the levels of reactive oxygen species (ROS) in the guard cells. Further, guard cells of mutant plants showed faster ABA-induced closure compared to wild type, suggesting that flavonols may reduce the ABA-dependent ROS burst that drives stomatal closing (Watkins et al. 2014). Curiously, flavonols levels were positively regulated in guard cells by ethylene treatment in the wild type, but not in an ethylene-insensitive mutant, suggesting an ethylene-regulated mechanism of flavonols controlling ROS burst under ABA signaling (Watkins et al. 2014). Similarly, it was also demonstrated that in tomato (Solanum lycopersicum), ABAinduced ROS accumulation is followed by stomatal closure (Watkins et al. 2017). Ethylene treatment of wild-type tomato plants increased flavonol accumulation in guard cells; however, no flavonol increases were observed in Neverripe (Nr) plants, an ethylene receptor deficient mutant. Taken together, these results strongly suggest the roles of flavonols as important players during the ABA-dependent ROS production for the regulation of stomatal opening. Intriguingly, the link between flavonols and stomatal functioning was also observed in an independent recent study investigating metabolic components of water stress in a Meditteranean vineyard (Gago et al. 2017).

Returning to the hormone response it is clear that hormones are good targets to investigate guard cell metabolomics. Indeed, considerable attention has been paid to ABA, but the crosstalk between ABA and other hormones can potentially also affect stomatal movements. For instance, brassinosteroid and jasmonate can act concurrently with ABA promoting senescence and programmed cell death (Hossain et al. 2011; Zhang et al. 2009). Other hormones such as cytokinin, auxin, salicylic acid and ethylene have been showed to act antagonistically to ABA under water deficit conditions (Chen et al. 2013; Ha et al. 2012; Meguro and Sato 2014; Tanaka et al. 2005). Therefore, we believe that metabolomics tools for specific cells can be useful in order to evaluate the metabolic changes provoked by the hormone signaling network and improving methods for single cell hormone measurements will likely greatly increase our ability to understand and model hormonal aspects of the control of stomatal movements.
2.2 Response to high $\mathrm{CO}_{2}$ concentration

High ambient $\mathrm{CO}_{2}$ concentrations mediate closure of stomatal pores in plants and conversely low ambient $\mathrm{CO}_{2}$ concentration triggers the opening of stomatal pores. Within the context of the raising atmospheric $\mathrm{CO}_{2}$ concentration to understand how guard cells adjust their physiology and metabolism in response to $\mathrm{CO}_{2}$ is a key step for the development of plants better adapted to the shifting climate condition (Geng et al. 2017). Indeed, although the whole network of $\mathrm{CO}_{2}$ response is not fully clear, recent studies have addressed the molecular and cellular mechanisms mediating $\mathrm{CO}_{2}$ regulation of stomatal movements (Engineer et al. 2016; Zhang et al. 2018). For instance, changes in the metabolite profile in response to increases in $\mathrm{CO}_{2}$ concentration was investigated over time. For this propose mesophyll and guard cells protoplasts from $B$. napus were fed with sodium bicarbonate $\left(\mathrm{NaHCO}_{3}\right)$ (Misra et al. 2015b). In this study, targeted metabolite profiling in untreated and $\mathrm{NaHCO} 3$ treated mesophyll and guard cell was performed using LC-MRM-MS and GC-MS/MS based technologies, in order to identify 268 metabolites related to both, primary and secondary metabolism. Interestingly, opposing metabolic responses were observed between the two cell types, in that while mesophyll cells presented increases in amino acid, phenylpropanoid, redox metabolite, auxin and cytokinin contents all of which were decreased in treated guard cells. The outcome from both cell type metabolite profile revealed that 26 and 27 metabolites in mesophyll and guard cells were exclusively identified, respectively. Regarding primary metabolism, constant increase of malate was observed across the experiment in $\mathrm{NaHCO}_{3}$ treated guard cells. Additionally, in these cells increases in fructose, glucose, and mannose were observed at the early time-points (Misra et al. 2015b).

In another study by using three different approaches; GC-MS/MS, LC-MRM-MS, and LCTOF-MS it was able to successfully annotate 358 metabolites (Geng et al. 2016). In this study the metabolic responses in guard cell-enriched epidermal fragments of $B$. napus were evaluated in response to elevated $\mathrm{CO}_{2}(800 \mathrm{ppm})$ in a time-course experiment (over $1 \mathrm{~h}$ ). Interestingly, these authors reported changes in primary metabolites such as sugars, fatty acids, amino acids and nucleotides under elevated $\mathrm{CO}_{2}$ 
treatment. Additionally, ROS production increased and stomatal aperture decreased over the time. Curiously, following the previous findings in metabolic guard cell response to ABA (Zhu and Assmann 2017), alterations in flavonoid, organic acid, sugar, fatty acid, phenylpropanoid and amino acid metabolic pathways indicated changes in both primary and specialized metabolic pathways in guard cells. However, the novelty presented by this work was that after $10 \mathrm{~min}$ under elevated $\mathrm{CO}_{2}$ treatment the jasmonic acid biosynthesis pathway was significantly induced (Geng et al. 2016).

\subsection{Understanding the roles of Suc in guard cells}

For a long time sucrose was believed to exclusively play an osmolytic role in stomatal opening (Daloso et al. 2016a). However, by using metabolomics tools recent findings have not only challenged this claim but also proposed an energetic role of sucrose during lightinduced stomatal opening (for a complete overview about sucrose roles during stomatal movements please read Daloso et al. (2016a) and Lima et al. (2018)). The section below compiles interesting reports focused on the application of metabolomics tools to solve the open questions about guard cell metabolism.

The metabolic changes in guard cell-enriched epidermal fragments from tobacco (Nicotiana tabacum L.) during light-induced stomatal opening were evaluated alongside with isotope kinetic labelling experiment by feeding the guard cell-enriched epidermal fragments with $\mathrm{NaH}^{13} \mathrm{CO}_{3}$ under light conditions in order to understand the distribution of photosynthetic fluxes in guard cells (Daloso et al. 2015). By using a GC-TOF-MS platform it was observed that concomitant with the decrease in sucrose, there were increases in the level and ${ }^{13} \mathrm{C}$ enrichment of the TCA cycle-related metabolites. This report was the first evidence supporting the hypothesis that sucrose is catabolized within guard cells in order to provide carbon skeletons for organic acid production. Another important finding from this work was the qualitative demonstration that $\mathrm{CO}_{2}$ fixation in tobacco guard cells can be catalyzed both by ribulose-1,5-biphosphate carboxylase/oxygenase (Rubisco) and phosphoenolpyruvate carboxylase (PEPc) (Daloso et al. 2015).

A follow-up study was performed using transgenic tobacco plants specifically overexpressing SUCROSE
SYNTHASE 3 (SUS3) in guard cells (Daloso et al. 2016b). A kinetic isotope labeling experiment following the metabolic fate of $\mathrm{NaH}^{13} \mathrm{CO}_{3}$ during the darkto-light transition was performed using guard cellenriched epidermal fragments which were analyzed via GC-TOF-MS. Minor changes were observed in the metabolite profile of whole leaves, whereas increased fructose and decreased organic acids levels were observed in the transgenic plants. In good agreement with the results from the previous study, increased labeling of the TCA cycle-related metabolites was observed, suggesting that breakdown of sucrose is a mechanism providing carbon skeletons during stomatal opening (Daloso et al. 2016b).

Despite the above-discussed evidence, the direct proof that sucrose acts as an energetic substrate during the dark-to-light transition was still missing until earlier this year when the work using a combination of stomatal aperture assays and kinetic [U- $\left.{ }^{13} \mathrm{C}\right]$-sucrose isotope labelling experiments was published (Medeiros et al. 2018b). This work aimed to directly follow the fate of the carbons released from sucrose breakdown during light-induced stomatal opening. In this study GC-TOF-MS was used revealing rapid and high ${ }^{13} \mathrm{C}$ enrichment in fructose and glucose following dark-to-light transition. Clear ${ }^{13} \mathrm{C}$ enrichment in glycolysis and TCA cycle intermediates as well as glutamate and glutamine was also observed indicating activation of these pathways during light-induced stomatal opening. These new findings allowed a reevaluation of the current models concerning the role of sucrose in stomatal opening. It is now clear that during stomatal opening sucrose is degraded providing carbon skeletons for glutamine biosynthesis, however, the physiological reason behind this is, as yet, far from being understood (Lima et al. 2018; Medeiros et al. 2018b).

\subsection{Metabolic changes due to altered organic acids transport in guard cell}

Malate and fumarate have been highlighted as important players during stomatal movements. Given their importance in controlling stomatal movement, channels and transporters were recently identified and functionally characterized to be involved with organic acid transport at both plasma membrane and tonoplast of guard cells (Eisenach and De Angeli 2017; Martinoia 2018). In this context metabolomics approaches 
have been used in order to evaluate changes in the metabolism of both leaves and guard cells (Medeiros et al. 2016, 2017).

QUAC1 (Quick activating Anion Channel 1), also known as ALMT12, is a member of ALMT (Aluminum activated malate transporter) family, was identified as an ABA-dependent anion-selective channel at the guard cell plasma membrane responsible for malate efflux during stomatal closure in a voltagedependent manner (Meyer et al. 2010). Loss-offunction of QUAC1 resulted in an impaired kinetic of stomatal closure in response to dark and high $\mathrm{CO}_{2}$ levels as well as reduced ABA-induced stomatal closure coupled with significant changes in organic acid accumulation as well as increases in both stomatal and mesophyll conductance (Medeiros et al. 2016). By using the GC-TOF-MS system 40 metabolites related to primary metabolism were successfully annotated, showing relatively few changes in the metabolite profile of mutant leaves. Interestingly, looking at the organic acids levels, it was observed that maleic acid, malate, fumarate, succinate increased in the knockout lines. These results indicate that changes in organic acids homeostasis in guard cell can affect the whole leaf metabolism highlighting the coordination between mesophyll and guard cell metabolism.

A vacuolar malate transporter (tonoplast Dicarboxylate Transporter-tDT) was also recently characterized in Arabidopsis. tDT was considered the main malate transport system at the tonoplast and required for the proper accumulation of malate in Arabidopsis leaves (Emmerlich et al. 2003; Hurth et al. 2005). tDT was only recently functionally characterized (Frei et al. 2018). Highly purified tDT protein showed transport activity as malate and citrate $1: 1$ in an antiport mode, also accepting fumarate and succinate as substrates (Frei et al. 2018). However, the functional role of tDT in guard cells remained unclear until recently when the metabolic impact of the tDT absence was studied (Medeiros et al. 2017). This study also used GC-TOF-MS technology to assess metabolic changes in leaves and guard cell-enriched epidermal fragments of wild type and $t d t$ knockout lines. This study showed that manipulating vacuolar organic acid transport by suppressing tDT greatly impacts mitochondrial metabolism but has minor effects on stomatal and photosynthetic capacity. Interestingly, by comparing the metabolite profiles of leaves and guard cell-enriched epidermal fragments, intermediates of the tricarboxylic acid cycle were altered differently in the two tissues. For instance, lower malate and fumarate accumulation was observed in leaves but not in epidermal fragments (Medeiros et al. 2017). These findings confirmed the previous hypothesis of functional redundancy for organic acids transport at the tonoplast in guard cells (Meyer et al. 2011).

Recently the report of a new ALMT member (ALMT4) demonstrated it to be a phosphorylationdependent anion channel, releasing malate from the vacuole during stomatal closure in response to ABA (Eisenach et al. 2017). almt4 knockout mutants displayed normal stomatal opening, but by contrast to other organic acids transporters at the tonoplast, almt4 plants presented impaired stomatal closure in response to ABA, but not to darkness (Eisenach et al. 2017). Altogether these exciting findings suggest that independent mechanisms may be activated under specific conditions and individual organic acid transporters are regulated independently in a stimulusdependent manner at the tonoplast (Medeiros et al. 2018a).

\subsection{The guard cell metabolome during plant cell- microorganism interaction}

The interaction between plants and microorganisms is known to triggers signaling cascade and metabolic responses. However, the main issue of analyzing changes in the plant metabolic profile during the interaction plant cell-microorganism is avoiding contamination with metabolites from the coexisting microorganism (Pang et al. 2018). A very recent work addressed this issue by implementing an effective stable isotope labeling approach coupled to LCMRM-MS measurements (Pang et al. 2018). The plant bacterial pathogen Pseudomonas syringae pv. tomato DC3000 was incubated in isotope-labeled medium (Celtone complete medium with $>98 \%{ }^{13} \mathrm{C}$ and $>98 \%{ }^{15} \mathrm{~N}$ ). This procedure was used in order to differentiate plant metabolites from bacterial metabolites. This study suggested that bacterial infection may affect stomatal movement by reprograming the guard cell signaling network and primary metabolism. It was observed that at $30 \mathrm{~min}$ after bacterial infection the most affected pathways were related to amino acid metabolism. Whereas at $180 \mathrm{~min}$, aminoacyl-tRNA biosynthesis, the tricarboxylic acid (TCA) cycle, and 
carbon fixation as well as the biosynthesis of phenylalanine, tyrosine, and tryptophan were dramatically affected.

In summary, metabolite profiling has aided the identification of several novel interactions between the TCA cycle, photosynthesis and stomatal function as well as guard cell responses to both biotic and abiotic stresses. Due to the vast complexity of the metabolic and molecular regulatory pathways underlying guard cell function they remain not fully understood. However, the improvements of new technologies toward metabolomics approaches will help us to better understand stomatal responses. Furthermore, the usage of metabolic data into mathematical models can optimize predictions of stomatal behavior in a changing environment. Studies in this direction have been performed and are discussed in the following section.

\section{Metabolomics data for improving stomatal behavior predictions}

Transcriptomics, proteomics, and metabolomics studies carried out using guard cells as model have contributed substantially for our understanding on how plant cells sense and respond to environmental and endogenous signals such as relative air humidity, $\mathrm{CO}_{2}, \mathrm{ABA}$, and sucrose (Medeiros et al. 2015). All of the knowledge gained from these studies are useful for the establishment of systems biology approaches. Transcriptomic data has advantage over other omics platforms for the use in mathematical models given the higher coverage of transcriptomic techniques (Alseekh and Fernie 2018). Comparatively, proteomics and metabolomics platforms need substantial improvement to increase the number of analytes detected. This is an important issue for the creation of genomic scale metabolic models, in which several reactions of the metabolic network are included in the model (Hyduke et al. 2013). However, it is noteworthy that gene expression does not always correlate to protein expression/activity and subsequently to metabolic changes (Fernie and Stitt 2012; Lehmann et al. 2009). In this scenario, metabolomics approaches provide vital information by which to understand the structure and the regulation of metabolic networks as well as to enhance the predictive power of metabolic models.
Despite the fact that mass spectrometry-based metabolomics platforms have been widely used in plant biology, these platforms have only been recently used to investigate guard cell metabolism (Medeiros et al. 2015; Misra et al. 2015a). The establishment of a reproducible and reliable analytical platform is crucial for the performance of -omics studies, which can subsequently aid in the generation of mathematical models. Some models for leaf metabolism of C3, C4, and CAM plants have been published (Arnold and Nikoloski 2014; Cheung et al. 2014, 2015; Chew et al. 2014; Masakapalli et al. 2010, 2013; Pfau et al. 2018; Seaver et al. 2015; Shameer et al. 2018; Sweetlove et al. 2013; Wang et al. 2012). Recently the AraCORE model created for leaf primary metabolism (Arnold and Nikoloski 2014) has been adapted to model guard cell metabolism (Robaina-Estevez et al. 2017). Largescale omics data have been used to constrain different models and thus more faithfully predict metabolic fluxes through metabolic networks (Nikoloski et al. 2015; Orth et al. 2010). This is part of a systemic characterization of plants, in which the data generated is used either to create or to improve mathematical models, following a "design-build-test-learn" cycle (Sweetlove et al. 2017).

Existing models and their combinations have clearly contributed to the predictive modelling and refinement of the relationship between stomatal conductance and the players regulating stomatal function. Unfortunately, limited success in clarifying how changes in stomatal movements, by consequence water loss and $\mathrm{CO}_{2}$ gain, are affected by the interplay of environment, cellular levels, as well as the coordination between mesophyll and guard cells. The OnGuard platform is one of the first modelling approaches created specifically for guard cells (Hills et al. 2012). Although the possibility to analyze guard cell signaling pathways using the theory of biological networks was postulated much earlier (Hetherington and Woodward 2003). OnGuard is a software built based on the knowledge of transport and accumulation of important molecules for guard cell osmoregulation such as $\mathrm{K}^{+}, \mathrm{Cl}^{-}, \mathrm{Ca}^{+2}$, malate, and sucrose. Simulations of the transport of these molecules through both plasma and tonoplast membranes of guard cells can be now performed by OnGuard (Chen et al. 2012; Hills et al. 2012; Wang et al. 2014). Despite its great contribution to understand important process that regulates stomatal movements, OnGuard software is 
not able to predict metabolic alterations in guard cells. This is partially due to the relative scarcity of guard cell metabolomics data. However, given that recent metabolomics approaches (reviewed above) being adapted to study guard cells, this hurdle is no longer valid.

LC-MS and GC-MS-based metabolomics studies have provided important information regarding the guard cell response to ABA, bicarbonate, and sucrose (Daloso et al. 2015; Jin et al. 2013; Medeiros et al. 2018b; Misra et al. 2015b; Zhu and Assmann 2017). Furthermore, the establishment of a methodology to perform ${ }^{13} \mathrm{C}$-feeding experiments with the use of labelled substrates resolve a long debate regarding the role of sucrose for guard cell regulation and the mode of $\mathrm{CO}_{2}$ fixation found in guard cells (Daloso et al. 2015; Medeiros et al. 2018b). RubisCO-mediated $\mathrm{CO}_{2}$ fixation has long been thought to be absent in guard cells (Outlaw and Manchester 1979). However, the ${ }^{13} \mathrm{C}$ distribution found in guard cells subjected to light indicate a clear $\mathrm{CO}_{2}$ fixation mediated by both RubisCO and PEPc (Daloso et al. 2015). The results of this study were substantially different from those observed in the Arabidopsis rosette which is largely composed of mesophyll cells (Szecowka et al. 2013). Taking this into account, a systems biology study compared the $\mathrm{NaH}^{13} \mathrm{CO}_{3}$ distribution in mesophyll and guard cell protoplasts by combining flux predictions using a genome scale metabolic model and the ${ }^{13} \mathrm{C}$ distribution measured in both cells via $\mathrm{GC}-\mathrm{TOF}-$ MS (Robaina-Estevez et al. 2017). The modelling strategy of this work was based in previous published transcriptome data (Bates et al. 2012; Pandey et al. 2010) that were integrated into the AraCORE model (Arnold and Nikoloski 2014). As output, the new model, namely AraCOREred, provides cell-specific metabolic predictions of 455 reactions which comprise 374 primary metabolites of mesophyll and guard cells (Robaina-Estevez et al. 2017). Interestingly, the results of this work confirmed that guard cells have higher anaplerotic $\mathrm{CO}_{2}$ fixation by PEPc than mesophyll cells as well as regarding the source of sucrose and malate within guard cells.

The use of such genome scale, constraint-based metabolic models is important to understand the regulation of plant metabolism (Sweetlove et al. 2017). Mainly because the model can predict metabolic changes at subcellular level under different conditions, given that the input of signals and the output of the model can be manipulated according to the aim of the study (Medeiros et al. 2015; Orth et al. 2010). The AraCOREred model indicates that transcriptome data can be used to predict cell-specific metabolic changes. This model can then be used in the future to predict guard cell metabolic responses to ABA and sucrose, given the availability of transcriptome data under ABA and sucrose treatment (Bates et al. 2012; Bauer et al. 2013; Leonhardt et al. 2004; Pandey et al. 2010). However, it is important to highlight that AraCOREred model was created assuming the guard cell metabolism at steady states. Due to the dynamic nature of the guard cell metabolism, the current challenge is to model guard cells under nonsteady state condition, which would seem to be more physiologically relevant given the high plasticity of guard cell metabolism under varying conditions. Modelling strategies such as dynamic flux balance analysis seems to be great option to fulfil this gap. The establishment of such non-steady state modelling, while challenging, may increase the reliability of predictions by the current available models for guard cell functioning.

\section{Concluding remarks}

Over the past 5 years the application of metabolomics approaches in order to better understand guard cell metabolism and the mechanisms underlying the stomatal responses to environmental and endogenous cues has increased. Metabolite profiling of isolated or enriched-guard cells extracts has aided the identification of several novel interactions between the TCA cycle, photosynthesis, and stomatal function. Furthermore, guard cell metabolomics studies have fulfilled some important unsolved questions regarding the roles of sucrose and organic acids transport and metabolism during stomatal movements as well as the guard cell responses to water deficit, high $\mathrm{CO}_{2}$ concentrations, and plant defense against pathogens.

Alongside other omics technologies, metabolomics studies of the highly specialized guard cell have proven to be a powerful tool for understanding the hormonal and metabolic regulation of stomatal movements. This is particularly important since plant growth, development, and yield depend greatly of the fine control of plant-environment gas exchanges. Given the complexity of the interconnected networks 
governing stomatal movements under varying conditions, we argue that metabolomics approaches are highly valuable. An emerging technology that may greatly aid in this vein is metabolite imaging (Bjarnholt et al. 2014), which may soon be able to aid our understanding of metabolite movements between the mesophyll and guard cells. Ongoing systems biology approaches, combining data from different omics technologies will aid in elucidating the mechanisms underlying stomatal control and furthermore could ultimately unravel targets for modulation of stomatal responses to environment and towards the design of new strategies for engineering better plant performance in the field.

Acknowledgements Open access funding provided by Max Planck Society. This work was supported by funding from Max Plank Society, Conselho Nacional de Desenvolvimento Científico e Tecnológico (CNPq-Brazil, Grant 402511/2016-6, W.L.A), Fundação de Amparo à Pesquisa do Estado de Minas Gerais (W.L.A., FAPEMIG, Grants APQ-01078-15 and RED00053-16, W.L.A.). Research fellowships from CNPq-Brazil to W.L.A. and D.M.D and scholarships from Coordenação de Aperfeiçoamento de Pessoal de Nível Superior (CAPES-Brazil) to L.M.L and H.O.O. are gratefully acknowledged.

Open Access This article is distributed under the terms of the Creative Commons Attribution 4.0 International License (http:// creativecommons.org/licenses/by/4.0/), which permits unrestricted use, distribution, and reproduction in any medium, provided you give appropriate credit to the original author(s) and the source, provide a link to the Creative Commons license, and indicate if changes were made.

\section{References}

Alseekh S, Fernie AR (2018) Metabolomics 20 years on: what have we learned and what hurdles remain? Plant J 94:933-942. https://doi.org/10.1111/tpj.13950

Amoedo G, Talbott LD, Zeiger E (1996) Use of potassium and sucrose by onion guard cells during a daily cycle of osmoregulation. Plant Cell Physiol 35:575-579

Arnold A, Nikoloski Z (2014) Bottom-up metabolic reconstruction of Arabidopsis and its application to determining the metabolic costs of enzyme production. Plant Physiol 165:1380-1391. https://doi.org/10.1104/pp.114.235358

Assmann SM, Wang X-Q (2001) From milliseconds to millions of years: guard cells and environmental responses. Curr Opin Plant Biol 4:421-428. https://doi.org/10.1016/s13695266(00)00195-3

Bates GW et al (2012) A comparative study of the Arabidopsis thaliana guard-cell transcriptome and its modulation by sucrose. PLoS ONE 7:e49641. https://doi.org/10.1371/ journal.pone.0049641
Bauer $\mathrm{H}$ et al (2013) The stomatal response to reduced relative humidity requires guard cell-autonomous ABA synthesis. Curr Biol 23:53-57. https://doi.org/10.1016/j.cub.2012.11. 022

Bergmann DC, Sack FD (2007) Stomatal development. Annu Rev Plant Biol 58:163-181. https://doi.org/10.1146/ annurev.arplant.58.032806.104023

Bjarnholt N, Li B, D’Alvise J, Janfelt C (2014) Mass spectrometry imaging of plant metabolites-principles and possibilities. Nat Prod Rep 31:818-837. https://doi.org/10. 1039/c3np70100j

Blatt MR (2000) Cellular signaling and volume control in stomatal movements in plants. Ann Rev Cell Dev Biol 16:221-241. https://doi.org/10.1146/annurev.cellbio.16.1. 221

Chen Z-H, Hills A, Bätz U, Amtmann A, Lew VL, Blatt MR (2012) Systems dynamic modeling of the stomatal guard cell predicts emergent behaviors in transport, signaling, and volume control. Plant Physiol 159:1235-1251. https:// doi.org/10.1104/pp.112.197350

Chen L, Dodd IC, Davies WJ, Wilkinson S (2013) Ethylene limits abscisic acid- or soil drying-induced stomatal closure in aged wheat leaves. Plant Cell Environ 36:1850-1859. https://doi.org/10.1111/pce.12094

Cheung CYM, Poolman MG, Fell DA, Ratcliffe RG, Sweetlove LJ (2014) A diel flux balance model captures interactions between light and dark metabolism during day-night cycles in C3 and crassulacean acid metabolism leaves. Plant Physiol 165:917-929. https://doi.org/10.1104/pp.113. 234468

Cheung CYM, Ratcliffe RG, Sweetlove LJ (2015) A method of accounting for enzyme costs in flux balance analysis reveals alternative pathways and metabolite stores in an illuminated Arabidopsis leaf. Plant Physiol 169:1671-1682. https://doi.org/10.1104/pp.15.00880

Chew YH et al (2014) Multiscale digital Arabidopsis predicts individual organ and whole-organism growth. Proc Natl Acad Sci USA 111:E4127-E4136. https://doi.org/10.1073/ pnas. 1410238111

Daloso DM et al (2015) Tobacco guard cells fix CO2 by both Rubisco and PEPcase while sucrose acts as a substrate during light-induced stomatal opening. Plant Cell Environ 38:2353-2371. https://doi.org/10.1111/pce.12555

Daloso DM, dos Anjos L, Fernie AR (2016a) Roles of sucrose in guard cell regulation. New Phytol 211:809-818. https:// doi.org/10.1111/nph.13950

Daloso DM, Williams TC, Antunes WC, Pinheiro DP, Muller C, Loureiro ME, Fernie AR (2016b) Guard cell-specific upregulation of sucrose synthase 3 reveals that the role of sucrose in stomatal function is primarily energetic. New Phytol 209:1470-1483. https://doi.org/10.1111/nph.13704

Daloso DM, Medeiros DB, Dos Anjos L, Yoshida T, Araujo WL, Fernie AR (2017) Metabolism within the specialized guard cells of plants. New Phytol 216:1018-1033. https:// doi.org/10.1111/nph.14823

Dow GJ, Bergmann DC (2014) Patterning and processes: how stomatal development defines physiological potential. Curr Opin Plant Biol 21:67-74. https://doi.org/10.1016/j.pbi. 2014.06.007 
Eisenach C, De Angeli A (2017) Ion transport at the vacuole during stomatal movements. Plant Physiol 174:520-530. https://doi.org/10.1104/pp.17.00130

Eisenach C, Baetz U, Huck NV, Zhang J, De Angeli A, Beckers GJM, Martinoia E (2017) ABA-induced stomatal closure involves ALMT4, a phosphorylation-dependent vacuolar anion channel of Arabidopsis. Plant Cell 29:2552-2569. https://doi.org/10.1105/tpc.17.00452

Emmerlich V, Linka N, Reinhold T, Hurth MA, Traub M, Martinoia E, Neuhaus HE (2003) The plant homolog to the human sodium/dicarboxylic cotransporter is the vacuolar malate carrier. Proc Natl Acad Sci USA 100:11122-11126. https://doi.org/10.1073/pnas.1832002100

Engineer $\mathrm{CB}$ et al (2016) $\mathrm{CO}_{2}$ sensing and $\mathrm{CO}_{2}$ regulation of stomatal conductance: advances and open questions. Trends Plant Sci 21:16-30. https://doi.org/10.1016/j. tplants.2015.08.014

Fernie AR, Stitt M (2012) On the discordance of metabolomics with proteomics and transcriptomics: coping with increasing complexity in logic, chemistry, and network interactions scientific correspondence. Plant Physiol 158:1139-1145. https://doi.org/10.1104/pp.112.193235

Frei B, Eisenach C, Martinoia E, Hussein S, Chen XZ, Arrivault S, Neuhaus HE (2018) Purification and functional characterization of the vacuolar malate transporter tDT from Arabidopsis. J Biol Chem 293:4180-4190. https://doi.org/ 10.1074/jbc.ra117.000851

Gago J et al (2017) Integrative field scale phenotyping for investigating metabolic components of water stress within a vineyard. Plant Methods 13:90. https://doi.org/10.1186/ s13007-017-0241-z

Geng S, Misra BB, Armas E, Huhman DV, Alborn HT, Sumner LW, Chen S (2016) Jasmonate-mediated stomatal closure under elevated $\mathrm{CO}_{2}$ revealed by time-resolved metabolomics. Plant J 88:947-962. https://doi.org/10.1111/tpj. 13296

Geng S, Yu B, Zhu N, Dufresne C, Chen S (2017) Metabolomics and proteomics of Brassica napus guard cells in response to low $\mathrm{CO}_{2}$. Front Mol Biosci 4:51. https://doi.org/10. 3389/fmolb.2017.00051

Ha S, Vankova R, Yamaguchi-Shinozaki K, Shinozaki K, Tran L-SP (2012) Cytokinins: metabolism and function in plant adaptation to environmental stresses. Trends Plant Sci 17:172-179. https://doi.org/10.1016/j.tplants.2011.12.005

Hetherington AM, Brownlee C (2004) The generation of $\mathrm{Ca}^{2+}$ signals in plants. Annu Rev Plant Biol 55:401-427. https:// doi.org/10.1146/annurev.arplant.55.031903.141624

Hetherington AM, Woodward FI (2003) The role of stomata in sensing and driving environmental change. Nature 424:901. https://doi.org/10.1038/nature01843

Hills A, Chen Z-H, Amtmann A, Blatt MR, Lew VL (2012) OnGuard, a computational platform for quantitative kinetic modeling of guard cell physiology. Plant Physiol 159:1026-1042. https://doi.org/10.1104/pp.112.197244

Hossain MA, Munemasa S, Uraji M, Nakamura Y, Mori IC, Murata Y (2011) Involvement of endogenous abscisic acid in methyl jasmonate-induced stomatal closure in Arabidopsis. Plant Physiol 156:430-438. https://doi.org/10. 1104/pp.111.172254

Hurth MA et al (2005) Impaired pH homeostasis in Arabidopsis lacking the vacuolar dicarboxylate transporter and analysis of carboxylic acid transport across the tonoplast. Plant Physiol 137:901-910. https://doi.org/10.1104/pp.104. 058453

Hyduke DR, Lewis NE, Palsson BØ (2013) Analysis of omics data with genome-scale models of metabolism. Mol BioSyst 9:167-174. https://doi.org/10.1039/c2mb25453k

Israelsson M, Siegel RS, Young J, Hashimoto M, Iba K, Schroeder JI (2006) Guard cell ABA and $\mathrm{CO}_{2}$ signaling network updates and $\mathrm{Ca}^{2+}$ sensor priming hypothesis. Curr Opin Plant Biol 9:654-663. https://doi.org/10.1016/j.pbi. 2006.09.006

Jezek M, Blatt MR (2017) The membrane transport system of the guard cell and its integration for stomatal dynamics. Plant Physiol 174:487-519. https://doi.org/10.1104/pp.16. 01949

Jin X, Wang R-S, Zhu M, Jeon BW, Albert R, Chen S, Assmann SM (2013) Abscisic acid-responsive guard cell metabolomes of Arabidopsis wild type and gpal G-protein mutants. Plant Cell 25:4789-4811. https://doi.org/10.1105/ tpc. 113.119800

Kim T-H, Böhmer M, Hu H, Nishimura N, Schroeder JI (2010) Guard cell signal transduction network: advances in understanding abscisic acid, $\mathrm{CO}_{2}$, and $\mathrm{Ca}^{2+}$ signaling. Annu Rev Plant Biol 61:561-591. https://doi.org/10.1146/ annurev-arplant-042809-112226

Kollist H, Nuhkat M, Roelfsema MRG (2014) Closing gaps: linking elements that control stomatal movement. New Phytol 203:44-62. https://doi.org/10.1111/nph.12832

Lawson T, Simkin AJ, Kelly G, Granot D (2014) Mesophyll photosynthesis and guard cell metabolism impacts on stomatal behaviour. New Phytol 203:1064-1081. https:// doi.org/10.1111/nph.12945

Lehmann M et al (2009) The metabolic response of Arabidopsis roots to oxidative stress is distinct from that of heterotrophic cells in culture and highlights a complex relationship between the levels of transcripts, metabolites, and flux. Mol Plant 2:390-406. https://doi.org/10.1093/mp/ssn080

Leonhardt N, Kwak JM, Robert N, Waner D, Leonhardt G, Schroeder JI (2004) Microarray expression analyses of Arabidopsis guard cells and isolation of a recessive abscisic acid hypersensitive protein phosphatase 2C mutant. Plant Cell 16:596-615. https://doi.org/10.1105/ tpc. 019000

Lima VF, Medeiros DB, Dos Anjos L, Gago J, Fernie AR, Daloso DM (2018) Toward multifaceted roles of sucrose in the regulation of stomatal movement Plant Signal Behav 13:e1494468. https://doi.org/10.1080/15592324.2018. 1494468

Lu P, Zhang SQ, Outlaw WH, Riddle KA (1995) Sucrose: a solute that accumulates in the guard-cell apoplast and guard-cell symplast of open stomata. FEBS Lett 362:180-184. 5793(95)00239-6

Martinoia E (2018) Vacuolar transporters-companions on a longtime journey. Plant Physiol 176:1384-1407. https:// doi.org/10.1104/pp.17.01481

Masakapalli SK, Le Lay P, Huddleston JE, Pollock NL, Kruger NJ, Ratcliffe RG (2010) Subcellular flux analysis of central metabolism in a heterotrophic Arabidopsis cell suspension using steady-state stable isotope labeling. Plant Physiol 152:602-619. https://doi.org/10.1104/pp.109.151316 
Masakapalli SK, Kruger NJ, Ratcliffe RG (2013) The metabolic flux phenotype of heterotrophic Arabidopsis cells reveals a complex response to changes in nitrogen supply. Plant $\mathbf{J}$ 74:569-582. https://doi.org/10.1111/tpj.12142

Medeiros DB, Daloso DM, Fernie AR, Nikoloski Z, Araujo WL (2015) Utilizing systems biology to unravel stomatal function and the hierarchies underpinning its control. Plant Cell Environ 38:1457-1470. https://doi.org/10.1111/pce. 12517

Medeiros DB et al (2016) Enhanced photosynthesis and growth in atquacl knockout mutants are due to altered organic acid accumulation and an increase in both stomatal and mesophyll conductance. Plant Physiol 170:86-101. https://doi. org/10.1104/pp.15.01053

Medeiros DB et al (2017) Impaired malate and fumarate accumulation due to the mutation of the tonoplast Dicarboxylate Transporter has little effects on stomatal behavior. Plant Physiol 175:1068-1081. https://doi.org/10.1104/pp. 17.00971

Medeiros DB, Fernie AR, Araújo WL (2018a) Discriminating the function(s) of guard cell ALMT channels. Trends Plant Sci 23:649-651. https://doi.org/10.1016/j.tplants.2018.06. 006

Medeiros DB, Perez Souza L, Antunes WC, Araujo WL, Daloso DM, Fernie AR (2018b) Sucrose breakdown within guard cells provides substrates for glycolysis and glutamine biosynthesis during light-induced stomatal opening. Plant J 94:583-594. https://doi.org/10.1111/tpj.13889

Meguro A, Sato Y (2014) Salicylic acid antagonizes abscisic acid inhibition of shoot growth and cell cycle progression in rice. Sci Rep 4:4555. https://doi.org/10.1038/srep04555

Meyer S et al (2010) AtALMT12 represents an R-type anion channel required for stomatal movement in Arabidopsis guard cells. Plant J 63:1054-1062. https://doi.org/10.1111/ j.1365-313x.2010.04302.x

Meyer S, Scholz-Starke J, De Angeli A, Kovermann P, Burla B, Gambale F, Martinoia E (2011) Malate transport by the vacuolar AtALMT6 channel in guard cells is subject to multiple regulation. Plant J 67:247-257. https://doi.org/10. 1111/j.1365-313x.2011.04587.x

Misra BB, Acharya BR, Granot D, Assmann SM, Chen S (2015a) The guard cell metabolome: functions in stomatal movement and global food security. Front Plant Sci 6:334. https://doi.org/10.3389/fpls.2015.00334

Misra BB, de Armas E, Tong Z, Chen S (2015b) Metabolomic responses of guard cells and mesophyll cells to bicarbonate. PLoS ONE 10:e0144206. https://doi.org/10.1371/ journal.pone. 0144206

Mott KA (2009) Opinion: stomatal responses to light and $\mathrm{CO}_{2}$ depend on the mesophyll. Plant Cell Environ 32:1479-1486. https://doi.org/10.1111/j.1365-3040.2009. 02022.x

Nikoloski Z, Perez-Storey R, Sweetlove LJ (2015) Inference and prediction of metabolic network fluxes. Plant Physiol 169:1443-1455. https://doi.org/10.1104/pp.15.01082

Orth JD, Thiele I, Palsson BØ (2010) What is flux balance analysis? Nat Biotechnol 28:245. https://doi.org/10.1038/ nbt. 1614

Outlaw WH, Manchester J (1979) Guard cell starch concentration quantitatively related to stomatal aperture. Plant Physiol 64:79-82. https://doi.org/10.1104/pp.64.1.79
Pandey S et al (2010) Boolean modeling of transcriptome data reveals novel modes of heterotrimeric $\mathrm{G}$ protein action. Mol Syst Biol 6:372. https://doi.org/10.1038/msb.2010.28

Pang Q, Zhang T, Wang Y, Kong W, Guan Q, Yan X, Chen S (2018) Metabolomics of early stage plant cell-microbe interaction using stable isotope labeling. Front Plant Sci 9:760. https://doi.org/10.3389/fpls.2018.00760

Pfau T, Christian N, Masakapalli SK, Sweetlove LJ, Poolman MG, Ebenhöh O (2018) The intertwined metabolism during symbiotic nitrogen fixation elucidated by metabolic modelling. Sci Rep 8:12504. https://doi.org/10.1038/ s41598-018-30884-X

Robaina-Estevez S, Daloso DM, Zhang Y, Fernie AR, Nikoloski Z (2017) Resolving the central metabolism of Arabidopsis guard cells. Rep 7:8307. https://doi.org/10.1038/s41598017-07132-9

Roelfsema MRG, Hedrich R (2005) In the light of stomatal opening: new insights into 'the Watergate'. New Phytol 167:665-691. https://doi.org/10.1111/j.1469-8137.2005. 01460.x

Santelia D, Lawson T (2016) Rethinking guard cell metabolism. Plant Physiol 172:1371-1392. https://doi.org/10.1104/pp. 16.00767

Santelia D, Lunn JE (2017) Transitory starch metabolism in guard cells: unique features for a unique function. Plant Physiol 174:539-549. https://doi.org/10.1104/pp.17.00211

Schroeder JI, Allen GJ, Hugouvieux V, Kwak JM, Waner D (2001) Guard cell signal transduction. Annu Rev Plant Physiol Plant Mol Biol 52:627-658. https://doi.org/10. 1146/annurev.arplant.52.1.627

Seaver SMD, Bradbury LMT, Frelin O, Zarecki R, Ruppin E, Hanson AD, Henry CS (2015) Improved evidence-based genome-scale metabolic models for maize leaf, embryo, and endosperm. Front Plant Sci 6:142. https://doi.org/10. 3389/fpls.2015.00142

Shameer S, Baghalian K, Cheung CYM, Ratcliffe RG, Sweetlove LJ (2018) Computational analysis of the productivity potential of CAM. Nat Plants 4:165-171. https://doi.org/ 10.1038/s41477-018-0112-2

Sweetlove LJ, Williams TR, Cheung CYM, Ratcliffe RG (2013) Modelling metabolic $\mathrm{CO}_{2}$ evolution-a fresh perspective on respiration. Plant Cell Environ 36:1631-1640. https:// doi.org/10.1111/pce.12105

Sweetlove LJ, Nielsen J, Fernie AR (2017) Engineering central metabolism - a grand challenge for plant biologists. Plant J 90:749-763. https://doi.org/10.1111/tpj.13464

Szecowka M et al (2013) Metabolic fluxes in an illuminated Arabidopsis rosette. Plant Cell 25:694-714. https://doi.org/ 10.1105/tpc.112.106989

Talbott LD, Zeiger E (1993) Sugar and organic acid accumulation in guard cells of Vicia faba in response to red and blue light. Plant Physiol 102:1163-1169. https://doi.org/ 10.1104/pp.102.4.1163

Talbott LD, Zeiger E (1996) Central roles for potassium and sucrose in guard-cell osmoregulation. Plant Physiol 111:1051-1057. https://doi.org/10.1104/pp.111.4.1051

Tanaka Y, Sano T, Tamaoki M, Nakajima N, Kondo N, Hasezawa S (2005) Ethylene inhibits abscisic acid-induced stomatal closure in Arabidopsis. Plant Physiol 138:2337-2343. https://doi.org/10.1104/pp.105.063503 
Vavasseur A, Raghavendra AS (2005) Guard cell metabolism and $\mathrm{CO}_{2}$ sensing. New Phytol 165:665-682. https://doi. org/10.1111/j.1469-8137.2004.01276.x

Wang C, Guo L, Li Y, Wang Z (2012) Systematic comparison of $\mathrm{C} 3$ and $\mathrm{C} 4$ plants based on metabolic network analysis. BMC Syst Biol 6:S9. https://doi.org/10.1186/1752-05096-s2-s9

Wang Y, Hills A, Blatt MR (2014) Systems analysis of guard cell membrane transport for enhanced stomatal dynamics and water use efficiency. Plant Physiol 164:1593-1599. https://doi.org/10.1104/pp.113.233403

Watkins JM, Hechler PJ, Muday GK (2014) Ethylene-induced flavonol accumulation in guard cells suppresses reactive oxygen species and moderates stomatal aperture. Plant Physiol 164:1707-1717. https://doi.org/10.1104/pp.113. 233528

Watkins JM, Chapman JM, Muday GK (2017) Abscisic acidinduced reactive oxygen species are modulated by flavonols to control stomata aperture. Plant Physiol 175:1807-1825. https://doi.org/10.1104/pp.17.01010

Zhang S, Cai Z, Wang X (2009) The primary signaling outputs of brassinosteroids are regulated by abscisic acid signaling. Proc Natl Acad Sci USA 106:4543-4548. https://doi.org/ 10.1073/pnas.0900349106

Zhang et al (2018) Insights into the molecular mechanisms of $\mathrm{CO}_{2}$-mediated regulation of stomatal movements. Curr Biol 28:R1356-R1363. https://doi.org/10.1016/j.cub.2018. 10.015

Zhu M, Assmann SM (2017) Metabolic signatures in response to abscisic acid (ABA) treatment in Brassica napus guard cells revealed by metabolomics. Sci Rep 7:12875. https:// doi.org/10.1038/s41598-017-13166-w

Publisher's Note Springer Nature remains neutral with regard to jurisdictional claims in published maps and institutional affiliations. 